\title{
LA ENSAYÍSTICA DE LISÍMACO CHAVARRÍA
}

Francisco Rodríguez Cascante

\section{(9) $(1) \Theta \Theta$}

Esta obra está bajo una licencia Creative Commons

Reconocimiento-No Comercial-Sin Obra Derivada 



\title{
LA ENSAYÍSTICA DE LISÍMACO CHAVARRÍA
}

\author{
THE ESSAYS BY LISÍMACO CHAVARRÍA
}

\author{
Francisco Rodríguez Cascante
}

\begin{abstract}
RESUMEN
La ensayística de Lisímaco Chavarría Palma (1873-1913) constituye un entramado discursivo multiforme y dialógico, en el cual se abordan distintas temáticas de gran relevancia para la cultura costarricense: el periodismo, la educación, la herencia indígena, las artes, la crítica literaria, la política y la identidad cultural. Su labor ensayística se divide en dos etapas: 1896-1903 y 1904 hasta 1911. En este artículo se estudian las preocupaciones ensayísticas del autor ramonense, prestando atención a los dos períodos de su producción, y vinculando estas textualizaciones con los caminos del pensamiento de su contexto, finales del siglo XIX y principios del XX.

Palabras clave: literatura costarricense, modernismo, ensayística, Lisímaco Chavarría Palma, crítica cultural.
\end{abstract}

\begin{abstract}
The essays written by Lisímaco Chavarría Palma (1873-1913) constitute a multiform and dialogical discursive framework in which various themes of great relevance for the Costa Rican culture are addressed, namely, journalism, education, indigenous inheritance, arts, literary criticism, politics, and cultural identity. His essays are divided into two stages: 1896-1903 and 1904 through 1911. This article studies the essay writing worries of this Ramonense author, paying close attention to his works and liking such texts to the paths of thought from their context, namely, the end of the XIX century and the beginning of the XX century.

Key words: Costa Rican literature, modernism, essay writing, Lisímaco Chavarría Palma, cultural criticism.
\end{abstract}

\section{Introducción}

Si bien fue la poesía el género al que prestó mayor dedicación Lisímaco Chavarría, su ensayística ocupa un importante lugar en su producción literaria. Se trata de un entramado discursivo que cultivó durante su corta y abundante vida intelectual. Su labor ensayística se divide en dos etapas, una inicial que abarca el período 1896-1903, debido a que al año siguiente

Dr. Francisco Rodríguez Cascante. Universidad de Costa Rica. Catedrático en la Sede de Occidente. Costa Rica. Correo electrónico: francisco.rodriguezcascante@ucr.ac.cr

Recepción: 15- 05- 2016

Aceptación: 26- 07- 2016 
Chavarría publicará (bajo del nombre de Rosa Corrales, su primera esposa) su primer libro (Orquídeas), ${ }^{1}$ constituyéndose su escritura literaria en una producción reconocida en el campo cultural costarricense. La segunda etapa va desde 1904 hasta 1911 y es el período de mayor madurez en su producción ensayística.

Si se considera el ensayo en tanto "interpretación ideológica y persuasiva de algún objeto producto de la cultura, de un proceso cultural o, incluso, de una cultura en su totalidad" (González-Picado, 1993, p. 8), se puede sostener que el trabajo de Chavarría Palma se orientó a la comprensión de una diversidad de procesos culturales, todos ellos conformadores de la cultura costarricense y centroamericana.

En este artículo se estudian las preocupaciones ensayísticas del autor ramonense, prestando atención a las dos etapas de su producción, y vinculando estas textualizaciones con las orientaciones del pensamiento de su contexto, finales del siglo XIX y principios del XX.

\section{Los ensayos iniciales (1896-1903)}

En esta ensayística inicial, el autor muestra interés por variados temas: la figura de Dios y sus relaciones con el ser humano, el papel de la obra de arte en el seno de la sociedad, lo cual aparece en textos dedicados a la escultura y al arte en general; la consideración sobre la herencia indígena nacional, la crítica literaria y uno de los temas privilegiados por el poeta: el papel de la educación en el desarrollo del país. Cabe señalar que esta última orientación ensayística está determinada por la labor pedagógica que desarrolló Chavarría entre 1900 y 1903 como maestro en escuelas rurales, ${ }^{2}$ situación que se explica por la falta de maestros titulados en el país a raíz de la numerosa apertura de nuevos centros educativos. ${ }^{3}$

Este conjunto de ensayos son los siguientes: "Dios" (1896), "Escultura clásica (primera parte)" (1896), "Escultura clásica (segunda parte)" (1896), "Arte" (1896), "La primavera" (1897), "Los descendientes de Pacacua" (1901), "El periodista" (1902) y "Romances" (1903). ${ }^{4}$

Aunque la presencia de temas bíblicos es escasa en el ensayo hispanoamericano (Maíz, 2013, p. 69), Lisímaco Chavarría inicia su trayectoria ensayística ocupándose de una reflexión teológica en 1896. El interés de este escrito consiste en el esfuerzo del joven autor por distinguir la presencia divina en el espacio tiempo mediante la estilización del lenguaje modernista. Dada la imposibilidad de la mostración positiva, el ensayista acude a la metáfora para dar cuenta de la omnipresencia divina: "mi mente solo lo concibe como una tea luminosa que hiere con su luz la conciencia de los mortales." (2013, p. 366). Pero Dios es más que lenguaje, es la causa primordial y también el origen de la inteligencia y de todo lo existente. Por ello, el ensayista echa mano de una concepción panteísta sobre la figura divina y critica la falsa ilusión del ateísmo: “...en el espacio infinito en que se balancean armónicamente millares de mundos, está escrito con inmensurables caracteres, el nombre del Creador para ser leído por los hombres de las diferentes razas y naciones" (2013, p. 366).

Esta reflexión sobre Dios como causa creadora y figura presente en todos los seres y los objetos, no será continuada en el trabajo ensayístico. Este texto inaugural es el primer asomo de exploración de la capacidad argumentativa y estilística del lenguaje expositivo, que es nuevamente puesto en acto en otro ejercicio de elevadas intenciones poéticas: el ensayo "La primavera", escrito un año después de "Dios".

Este trabajo es una aguda y nostálgica evocación de la niñez, asociada con la estación primaveral de la vida humana. La comparación argumenta que la infancia es la primavera del sujeto y su brevedad es el precio de su belleza y felicidad. Esta primera etapa vital del ser 
humano es comparada con el inicio de la estación que da vida y engendra la fuerza del despertar a los mejores momentos de la existencia, libre de responsabilidades y ávida del conocimiento del mundo, el cual aparece como un espacio de armonía y felicidad:

\begin{abstract}
Cuando veo los maizales peinados por las brisas húmedas; cuando veo las flores lozanas y frescas columpiarse airosas sobre su tallo, ostentando las cristalinas perlas que el rocío deposita en sus corolas; cuando contemplo el risco o la pradera, dorados por el sol de la mañana, recuerdo mi infancia que envolvió el pasado; recuerdo aquellos días sin plomizos nubarrones, aquellas horas fugitivas, que terminaron en crudos desengaños. Sí, entonces siento humedecerse mis ojos, ya no de gozo, sino porque veo perderse allá en lontananza, en el ocaso de mi pasado, aquellas horas de ventura, aquellos días de mi niñez. (Chavarría, 2013, p. 373)
\end{abstract}

Esta construcción nostálgica de la niñez como pérdida del paraíso, es uno de los tópicos más destacados del género autobiográfico y poético cuando se rememora el pasado que nunca más se volverá a vivir. ${ }^{5}$ La niñez es construida como objeto del deseo, utopía añorada y abandonada para siempre, como se nota en este ensayo de Chavarría, donde esta reconstrucción de la infancia está asociada con la fuga del tiempo y la nostalgia y elaborada mediante una literariedad que es la única capaz de restituir metafóricamente ese no lugar utópico del pasado como equilibrio y tiempo de felicidad e inocencia. Estamos en presencia del ensayo como género literario, es decir, como afirma Hirshbein, del género que "expresa en efecto un pensamiento, pero es un pensamiento creador e informal, impulsado por la imaginación, que es artísticamente creadora y busca siempre una nueva forma. Y solamente adquiere existencia literaria por la intencionalidad estética, por ese afán de crear belleza.” (1998, p. 699).

Pero el ensayo también es búsqueda de conocimiento (Earle, 1982, p. 48). Así lo muestran los textos lisimaquianos iniciales dedicados a la crítica de artes plásticas: "Escultura clásica (primera parte)", "Escultura clásica (segunda parte)" y "Arte”. En los dos primeros el autor estima que la escultura es el fruto de la madurez de las civilizaciones, por lo cual considera que debe ser apoyada por los gobiernos, situación que no se presenta en la Costa Rica de su época. Luego de esta crítica, pasa a desarrollar la idea de que para que se pueda realizar buena escultura es necesario que el artista se dedique al estudio de la teoría escultórica, ya que no es suficiente la inspiración, y dentro de estos análisis, la anatomía debe ocupar la atención del escultor en demasía, porque le permite plasmar toda la gama de variantes en los caracteres humanos.

El tercer ensayo es una crítica apologética de la obra del escultor ramonense Lico Rodríguez, el especialista imaginero que en sus obras ha logrado transmitir, desde la perspectiva de Chavarría, un cúmulo de experiencias semióticas a sus creaciones, alejándolas del estereotipo y la rigidez materiales. Pone, como ejemplo, la obra de Rodríguez "Cristo del Sepulcro", de la cual resalta la capacidad del escultor para trasmitirle vida artística a su trabajo:

\footnotetext{
...aquel rostro ya sin vida, pálido, con esa palidez del lirio enfermo, ensangrentado, que parece ser robado al verdadero Jesús después de muerto; con aquel reposo de los músculos de la cara que ostenta el cadáver cuando la insensibilidad ha cortado el movimiento, aquel cuerpo bien estudiado y bien sentido; asoma ese frío de difunto y la rigidez del cadáver. Ahora, si fijamos nuestra atención en el colorido, encontraremos la palidez del nardo en el invierno y la transparencia del moribundo, sin nada de extravagancia, sin nada de inmaterial, próximo a espirar, y comprenderemos cómo ha penetrado, cómo se ha empapado de la naturaleza, su única maestra, su única escuela. (2013, p. 370)
}

Por otra parte, también está presente en este corpus inicial la consideración de la herencia indígena en la cultura costarricense, específicamente en el texto "Los descendientes de Pacacua", escrito producto de su estancia como maestro en Tabarcia de Mora, experiencia que lo hace considerar el pasado regional y la cultura huetar que habitó la zona y de la cual aún se conservan registros. 
En dicho ensayo, Chavarría realiza una interpretación de la herencia de esa cultura, y observa el empleo de los ritos funerarios, los cuales describe con la mirada interesada del investigador que analiza las costumbres sin compararlas con las mestizas. Desde este punto de vista, este trabajo del autor ramonense se aleja de la mirada dominante sobre el indígena a principios del siglo XX en Costa Rica, que consistía en la idealización o en la condena. Por el contario, el autor valora positivamente la herencia cultural indígena producto de grupos que poseían una gran riqueza material y espiritual. Sobre los indígenas del presente afirma que son

\begin{abstract}
amantes de unas fiestas que llaman chichadas, porque en ellas no falta la chicha de maíz o sea el osoro y la taíra; con las que se ponen unas monas de siete zuelas. [...] Lo mismo muy hábiles en algunas manufacturas, como sombreros de pita, que tejen con una destreza asombrosa, tules, que son unos sombreros de otra planta textil que llevan ese mismo nombre, petaquillas, cigarreras y petates. (2013, pp. 376-377)
\end{abstract}

La mirada de Chavarría se distancia de los prejuicios raciales que propagó el biologicismo racialista del siglo XIX, y estima que los indios no son razas diferentes, y que el desprecio hacia sus prácticas culturales "equivale -como dice Lourdes Arizpe- a negar la creatividad de todo ser humano.” (1993, p. 343).

En el texto "El periodista", se evidencia otra de la preocupaciones iniciales del autor: el papel de la prensa. Cabe recordar que Chavarría se dedicó al periodismo desde que abandonó su trabajo como maestro. En el año 1904 fue propietario de dos periódicos: El Centinela y Las Noticias y colaboró como redactor en la revista Páginas Ilustradas. Asimismo, en 1907 trabajó como jefe de información de La Prensa Libre.

En 1902 ya estaban latentes en él sus preocupaciones por la labor de la prensa en el país. A raíz de ello escribió esta especie de poética periodística donde considera el ejercicio de la prensa como parte indispensable en la formación de la ciudadanía. La labor periodística la estima un apostolado antes que un trabajo, una noble misión que debe coadyuvar para alcanzar el sendero del progreso. Sin embargo, es una tarea delicada porque si el periodista, en vez de construir, se convierte en vocero de malas intenciones, puede destruir y envilecer lo que de positivo tiene el oficio.

El enunciador del ensayo compara el trabajo del periodista con la prédica de Jesús, quien expresaba sus consejos con sabiduría. Por ello, quien labora en esta profesión debe tener varias virtudes: nobleza de alma, vastos conocimientos y honradez, elementos imprescindibles en alguien que está llamado a ser un apóstol cuyo objetivo es enseñar y guiar a su sociedad:

\footnotetext{
Él es el llamado a señalar el sendero más corto y menos escabroso que conduce a la prosperidad. Él es el faro que se yergue sobre los escollos de la humanidad para irradiar su luz benefactora sobre las multitudes o en las conciencias ávidas de lumbre, él es el responsable de misión tan delicada y sacrosanta y si en él debe hallarse encarnado todo esto, es un apóstata, un fementido, un apóstol traidor si no cumple con el deber que le impone el apostolado del periodismo. (Chavarría, 2013, p. 386)
}

El último de estos ensayos iniciales inaugura otra de las temáticas que es de gran importancia en la obra de Chavarría: la crítica literaria. El breve texto "Romances" es un comentario a la obra homónima de Aquileo Echeverría publicada ese año de 1903 por la Imprenta Alsina. Con este ensayo se estrena Lisímaco en el campo de la crítica literaria, y lo hace dando cuenta de uno de sus temas favoritos: la representación de las costumbres nacionales. Del libro de su compatriota destaca su realismo y el acercamiento a las circunstancias populares que le sirvieron de inspiración a Aquileo: "Él ha sorprendido a nuestras sencillas y hermosas campesinas camino de la fuente con la tinaja de arcilla de Alajuelita en el cuadril..." (2013, p. 388), afirma, y continúa mostrando que efectivamente, 
Echeverría no hizo más que verosimilizar la realidad circundante que le tocó vivir, con lo cual aportó a la literatura costarricense un conjunto de cuadros vivos que merecían ser conocidos y disfrutados mediante la escritura literaria.

\section{La ensayística como crítica cultural}

La labor ensayística posterior de Lisímaco Chavarría se mantiene hasta los últimos días de su trayectoria intelectual, y tal práctica lo condujo por el camino que trazó en sus ensayos iniciales: una vocación poética irrenunciable y un afán reflexivo sobre los diversos componentes de las culturas nacionales e internacionales, que lo constituyen en tanto cronista de su tiempo. De estas preocupaciones son fundamentales la crítica de la educación, la crítica de artes, la crítica literaria y el análisis sociopolítico.

\section{La educación: senda hacia el progreso}

Chavarría fue un firme convencido de que la educación era el único camino posible hacia el desarrollo y el progreso. Su perspectiva era iluminista, ya que estimaba que el maestro era un depositario del conocimiento y el niño debía recibir ese saber, circunstancia que permitía no solamente el acceso a la información sino la transformación de sí mismo y del país, en un proceso que conducía de lo individual a lo colectivo, y que debía tener como fin el mejoramiento cultural y material de Costa Rica. El ensayo pedagógico, desde esta perspectiva, muestra que la vocación genérica de índole política y literaria confluyen "en su alcance pedagógico y ético, y se integran en una unidad histórica que contribuye a mostrar y probar los alcances y posibilidades de conocer la realidad social, política y económica" (MagallónAnaya, 1993, p. 235).

En el trabajo "Notas ligeras. Los maestros" (Chavarría, 2013, pp. 391-392) el autor devela las difíciles condiciones laborales que enfrentan los maestros que llegan a laborar a las escuelas rurales, especialmente en lo que se refiere a la desconfianza de las personas del lugar en relación con la preparación y la vocación del maestro. Por ello sostiene que los padres de familia deben confiar en los procesos de reclutamiento de la Inspección General de Enseñanza, la cual conoce a quienes envía con la misión de educar a los más jóvenes.

Considera Chavarría que el mejoramiento de los procesos de enseñanza en Costa Rica deben iniciar con la dignificación del maestro, con la reconsideración que él no debe ser visto como un funcionario público más, sino como un sujeto activo en la transformación del país, un punto de referencia intelectual y un gestor que ilumina a las futuras generaciones. Por ello clama ante las autoridades para que esta misión, equivalente al apostolado que plantea como tarea del periodista, sea noblemente estimada. Así lo propone en "La Enseñanza en Costa Rica I":

\footnotetext{
Quiero que la pobre caravana de apóstoles que predican sabiduría y siembran en las mentes juveniles las primeras simientes del saber, y en el corazón del párvulo, sanos principios de moral, no vivan relegados al olvido y que, antes que los méritos intelectuales, no triunfen la intriga y la prosapia distinguida. Quiero que la luz de las cualidades de tantos buenos maestros irradie, triunfe y sea utilizada para bien de las futuras generaciones de Costa Rica; quiero que concluyan las injusticias y las venganzas en el ramo de la enseñanza; quiero que haya equidad y bienestar en ese conjunto de propagadores de la luz intelectual que todos los años, resignados se dirigen a todas partes cargando en sus hombros de redentores, la cruz del infortunio y en su mente la idea atormentadora de ser víctimas de una venganza, si no se convierten en pusilánimes serviles; venganza que generalmente se dirige a la separación del maestro del miserable puesto que ocupa, con una destitución vergonzosa. (2013, p. 415)
} 
Este amargo periplo del maestro que es desechado y su recorrido poco valorado, junto con los procedimientos de evaluación de la burocracia, llevaron al intelectual a abandonar la práctica docente, renuncia lamentable que refiere en el emotivo ensayo “¡Ay de los vencidos!”:

\footnotetext{
En el apostolado del magisterio no he logrado llegar triunfante al Tabor de la escabrosa misión de la enseñanza; pero tengo la satisfacción de haber llevado la cruz un trecho bastante largo durante el lapso de cuatro años amargos, porque amarga es la misión del magisterio y más en esta mi querida patria, en donde el pobre obrero de la enseñanza tiene como el nauta eternamente ante su vista las asechanzas de los tifones del infortunio, y las amenazas de las trombas de las más amargas decepciones y adversidades, cuando no es juguete de intrigas rastreras y de calumnias ominosas. (2013, p. 410)
}

En su ensayística sobre la educación, Lisímaco Chavarría analiza la pedagogía como el camino que conducirá a Costa Rica a los derroteros de la ciencia, el progreso y la cultura ilustrada; sin embargo, este anhelado trayecto es obstaculizado por un aparato burocrático-estatal deficiente y anquilosado. Ante ello, el autor clama en sus ensayos por una urgente transformación que dignifique al maestro y lo valore como el agente de cambio que debería ser. En sus escritos, resalta la contradicción del ideal frente a una estructura administrativa contraproducente y deshumanizada. En este ámbito, como en las otras temáticas que aborda en su ensayística, se presenta un intelectual preocupado por el desarrollo del país y con una visión valiente y crítica.

\section{Artes plásticas y artes musicales: la densidad estética}

Los ensayos dedicados la crítica de artes plásticas son importantes para la comprensión de la disciplina artística en la Costa Rica de inicios del siglo XX. Estamos en un momento de desarrollo de este tipo de producciones y los escritos sobre tales actividades que escribió el autor dan cuenta de la formación de este campo estético. Estos ensayos tienen el objetivo de dar a conocer al público nacional los principales autores y temáticas que desarrollaban.

El ensayo "Exposición en la Escuela de Bellas Artes" propone una visión general de la estética, la cual se realiza en diversas manifestaciones, todas ellas igualmente válidas para expresar el "sentido" de la belleza. Con esto, para Lisímaco, existe una densidad formal de la estética que conforma la experiencia del arte, y esta se expresa por medios variados:

\footnotetext{
Si los cinceles pompeyanos dejaron eternizadas en los mármoles desenterrados en las ruinas de Pompeya y Herculano las costumbres de las víctimas del Vesubio; si las esfinges de Egipto nos dicen en lenguaje misterioso y mudo el poderío de los reyes egipcianos, y la estatua de Memnón la reverencia que los tebanos guardaban al hijo de Titón y Aurora, los pinceles de Zurbarán nos dicen los milagros de San Hugo, los del gran Rivera, el método de vida de San Jerónimo en el desierto y los de Velázquez, la fastuosa pompa de Felipe IV. (2013, p. 404)
}

Encontramos en este ensayo una propuesta estética: el arte es una manifestación superior de la belleza, en tanto plano suprasensible que posee concreciones particulares en prácticas artísticas. Esta aseveración la efectúa el autor con base en referencias clásicas de la cultura internacional (Ticiano, Miguel Ángel, Velázquez, Zurbarán, Van Dyck, Durán) para validar las manifestaciones producidas en el país.

En la percepción de Chavarría, el trabajo de Tomás Povedano es fundamental tanto en su capacidad expresiva por reelaborar sus raíces españolas en la representación pictórica, como por su labor pedagógica. Estima el autor que en el español se han reunido esas dos cualidades tan difíciles de conjuntar: el artista y el maestro: "La última exposición de dibujo y pintura, en la Escuela de Bellas Artes que está bajo su dirección, no solo ha demostrado que es un artista genial, sino un maestro verdadero." (2013, p. 405). Hay que recordar que el texto fue escrito 
en 1904, época en la cual el trabajo de las bellas artes era muy incipiente en Costa Rica. Esta circunstancia provoca que Chavarría defienda el valor estético en la labor de Povedano, así como su tesón para sacar adelante un proyecto inaugural en el orden de la enseñanza de esta disciplina.

A esto último remite el ensayo "Exposición en la Escuela de Bellas Artes. Galería de pintura", en el cual Lisímaco comenta los trabajos de los discípulos del pintor: A. Steiner, María Aurelia Castro, Adela Quesada, Angélica Lorenzo y Carolina Dent, en quienes ve el ensayista una generación renovada y conocedora de los principios estéticos que pregonaba el español.

De Povedano resalta la insistencia y su decidida lucha en un medio hostil y sin estímulo para el desarrollo de las artes plásticas: "Sí, este país ¿por qué no decirlo?, refractario a las Bellas Artes, debe mucho al artista de que trato. Como un nuevo Atlas, se ha echado un mundo sobre sus espaldas y lo ha sostenido con valentía y orgullo.” (2013, p. 406). Y efectivamente, esta labor en la Costa Rica de inicios del siglo XX constituía un trabajo solitario, ya que como bien observa Chavarría, los gobiernos no tenían dentro de sus prioridades la pedagogía artística.

Producto de su formación autodidacta, la crítica de artes que realiza Chavarría es de carácter impresionista, lo cual muestra más un interés divulgativo que analítico. Sin embargo, tuvo el gran acierto de dar a conocer los nuevos valores que el país estaba cultivando por medio de la escuela de Povedano.

Chavarría también dedicó un ensayo a la obra de Enrique Echandi: "Un artista”, en donde destaca la incansable labor de Echandi, a quien considera, además de trabajador, un soñador que renunció al mundo material para buscar las emociones del arte. Mira el ensayista en las obras de Echandi la expresión de una espiritualidad que lo hace comparar al costarricense con Murillo y Sanzio, en los cuales nota una distancia abismal con el materialismo. En Echandi valora el reino del color que permite el éxtasis del goce estético:

\footnotetext{
La luz del trópico descompuesta en mil cambiantes irisados, el tornasol de la mariposa azul que vaga como un pensamiento alado de flor en flor y de ribera en ribera, las transparencias de los rubíes de la granada excitante y agridulce, el blanco del jazmín del Cabo y el lila de las santalucías silvestres, se dan cita en la paleta de Enrique Echandi, quien con la magia de su pincel los torna en creaciones verdaderamente bellas. (2013, p. 493)
}

Además de fundacional, la crítica artística de Chavarría tiene el mérito de procurar encontrar modelos explicativos a los fenómenos estéticos aunque sea en el orden del impresionismo. En este sentido, sus agudas observaciones sobre una plástica que estaba en sus inicios, revelan erudición y acertadas referencias intertextuales en un ejercicio que procuraba mostrar al país las figuras más destacadas de su tiempo en la pintura.

El autor dedica dos ensayos a las artes musicales: "Concierto de la señorita Encarnación Mayoral" y "La flauta", donde retoma su disquisición sobre la estética. En el primer texto, estima Chavarría el arte como un estadio superior del espíritu que busca, además de la belleza, la bondad y la verdad, un acto mágico en el cual, como ocurrió en el concierto de la artista Mayoral, la realidad cotidiana se suspende para dar paso a la fantasía, donde todo lo mundano, mezquino y pequeño desaparece para ceder su lugar a la elevación artística:

El arte es como un luminoso alcázar; los que penetran en él sienten desaparecer del alma todas las
ruindades, todas las vilezas, todas las pesadumbres humanas que se retuercen y muerden, como crótalos
enfurecidos, en lo más sensible del sentimiento. El arte es una fuente de linfas milagrosas, los que sacian su
sed con esas aguas, se sienten con alientos para continuar la marcha fragosa de la existencia. (2013, p. 472)

Por otra parte, en el segundo ensayo el autor asume una enunciación en segunda persona para poetizar el origen y las capacidades expresivas de la flauta. Considera dicho 
instrumento como vivienda de los espíritus del ritmo, lugar donde habita el hada Armonía que es capaz de maravillar con sus hechizos a los amantes. El texto, provisto de una gran densidad poética, rememora que antes de la llegada de los españoles a América, ya los incas habían encontrado una forma fina y recta para tal instrumento, lo cual había develado los secretos de la música a esa civilización.

Chavarría compara la flauta con "una niña que gimiera por las flores que se fueron en el cristal en fuga del torrente" (2013, p. 522), y estima que el instrumento es capaz de expresar complejos sentimientos humanos: desde la alegría hasta las tristezas más dolorosas. Luego, recupera una breve historia de los materiales con que diversas culturas la han fabricado para señalar sus nobles orígenes y concluye diciéndole al instrumento que cuando parta hacia la eternidad, soñará "rimando una romanza dolorosa en una flauta de ébano y de marfil digna de uno de aquellos artistas de Corinto, allí junto al rosal que perfuma tu vivienda." (2013, p. 523). La flauta forma parte de la concepción lisimaquiana de la estética como vehículo expresivo de la subjetividad.

Esta teoría estética, donde la práctica estética es entendida como manifestación elevada del espíritu, tiene que ver con la "subjetivación de la perspectiva" (Weinberg, 2006, p. 49) propia del género ensayístico, en el cual un enunciador transmite más que un punto de vista: su propia experiencia del mundo a partir del universo sociocultural en donde vive.

\section{De España y América: la crítica literaria}

Chavarría dedica varios ensayos a la crítica literaria, en los cuales es notoria una preocupación por dar a conocer la literatura española, la latinoamericana y, con especial interés, la costarricense.

La ensayística dedicada a la literatura española destaca figuras notables. En el texto "Bajorrelieves. Rodolfo de Salazar y Felipe Trigo", Chavarría rescata la obra de estos dos autores. Del primero resalta su labor crítica, clara, escudriñadora y justa; por lo cual lo considera como una brújula que orienta la lectura. En cuanto a su producción literaria, recuerda su profundización en el paisaje y en las almas de sus personajes, por lo que lo compara con San Juan de la Cruz. Del segundo aborda su producción novelística, la cual observa en tanto revolucionaria por la forma clásica, donde encuentra más que a un novelista, a un filósofo y a un artista: "Para Trigo no guarda secretos el sentimiento, él se hunde en las concavidades del alma humana y torna a flor de sus novelas eróticas, con las perlas grises y brillantes de la voluptuosidad y de la locura pasionales." (2013, p. 495).

A la obra del poeta Eduardo de Ory dedica Chavarría un breve ensayo ("Bajorrelieves. Eduardo de Ory"). De este autor destaca la riqueza de una expresión poética que es capaz de representar la tranquilidad y el reposo para inmediatamente cambiar la tonalidad de dicción hacia un horizonte huracanado y violento donde toma lugar la grandilocuencia. De gran interés en esta valoración es que Chavarría propone que para triunfar en el campo artístico se necesita vigor intelectual, tenacidad y también una dosis de envidia de sus contemporáneos, ya que este sentimiento "consagra, así como el olvido y la indiferencia matan las más lozanas energías de la mentalidad." (2013, p. 508).

En relación con la literatura latinoamericana, Chavarría escribió los siguientes ensayos breves: "Bajorrelieves. Juan D’Sola y Eduardo Ortega", "Bajorrelieves. Amor de ensueño y de romanticismo, por Federico Uhrbach", "Bajorrelieve. Juan Ramón Molina” y "En España”.

En el primer ensayo destaca la obra en prosa del escritor venezolano Juan D'Sola, a quien considera un talentoso forjador de piedras preciosas; por ello lamenta su temprana 
muerte y exclama: "Una cruz de mármol negro para su tumba que cubre con sus alas de ángel del Silencio bajo el árbol de la Gloria.” (2013, p. 501), insistiendo en la modalidad literaria del ensayo, al distanciarse del lenguaje denotativo para profundizar en esa zona expresiva de carácter subjetivo que constituye el género. En este texto está presente esa dinámica de ida y vuelta entre el pensamiento crítico y la densidad imaginativa de la literatura, lo que de acuerdo con Teodosio Fernández (1990, p. 12), es constitutivo del género ensayístico.

Del poeta colombiano Eduardo Ortega, resalta Chavarría, empleando igualmente un discurso oscilante entre la poesía y la expresión de ideas, la capacidad que tuvo Ortega de condensar el sentimiento con la psicología, en una estructura modernista de gran calidad:

\footnotetext{
Visto al través del prisma azul de sus delicadas poesías se ve su alma como un loto que vibrara a las caricias de las emociones más sutiles, flor de sentimiento, flor de la más fina porcelana que saltaría en fragmentos al tocarla con las ondas más tenues de la brisa que juega en los jardines con las rosas y los lirios que saludan a la aurora. (2013, p. 502)
}

En el ensayo dedicado al poeta cubano Federico Uhrbach, destaca el ramonense la preocupación del autor por la forma estética: "Cada soneto suyo es un fino mosaico de catedral gótica, una ojiva en donde la luz solar se quiebra en mil colores luminosos." (2013, p. 436). Esa condición fragmentaria de la poesía de Uhrbach, que alude a su expresión vanguardista y hermética, es motivo, en el ensayo de Chavarría, de una defensa frente a sus detractores, quienes reclaman la dificultad interpretativa que tienen los lectores. Ante esto, Lisímaco insiste en la diferencia estética del lenguaje poético, el cual no tiene como fin la claridad comunicativa.

Una valoración semejante efectúa del poeta hondureño Juan Ramón Molina, en quien, de acuerdo con Chavarría, se articulan densidad formal, inspiración divina y afán pedagógico. Echando mano de su erudita biblioteca de referencias clásicas y contemporáneas, el ensayista caracteriza la profundidad de la obra poética de Molina como un vasto palimpsesto que asumió la mejor tradición del modernismo:

\footnotetext{
Tuvo para el epitalamio arrullos de paloma casta y cantos de tripolinas del Japón, para la poesía bucólica bebió en las mansas fuentes de Virgilio y de Teócrito, en la elegía fue sombrío como Silva y dulce como Alfredo de Musset, y cuando empuñaba la lira de acero, la lira pujante que en cada nota envuelve un alfanje y un dardo, era un inspirado rebelde que sabía de los atrevimientos del Águila de Patmos y de las actitudes de los leones del Sahara. (2013, p. 498)
}

En cuanto a su valoración de la novela En España, obra publicada en 1895 por el escritor nicaragüense Gustavo Guzmán, Chavarría destaca la corrección formal del texto y el interés argumental del relato. Considera que Guzmán es antes que nada un pintor por su habilidad descriptiva de distintos lugares españoles: el Escorial, la Puerta del Sol, Andalucía, Granada y San Sebastián. Afirma Chavarría que aún el que no ha viajado a España, por medio de esta novela se transporta a aquel país y es capaz de conocer de cerca varios espacios memorables de la región.

Los ensayos dedicados a la literatura costarricense son: "Medallón. Aquileo J. Echeverría", "Revista Semanal de Páginas Ilustradas IV", "Los huérfanos", "El estreno del domingo" y "Acordes de mi laúd". En ellos se observa una constante preocupación por valorar los autores reconocidos y dar a conocer a los jóvenes.

En el primero de ellos, Chavarría presta atención a las Concherías de Aquileo, específicamente a la capacidad del libro de modelizar segmentos de la vida cotidiana costarricense. Para Lisímaco, los textos de Echeverría, al textualizar los caracteres campesinos y sus formas de vida, logran dar una imagen cercana de la identidad popular del país: "Aquileo 
fue el mágico pintor de la vida montañesa de estos campos; en sus versos puso nuestro cantor toda la gama de colores de los prados y jardines patrios; cada romance suyo es una serpentina de las más brillantes ondas." (2013, p. 409). Desde esta perspectiva, vida y literatura son un mismo entramado, ya que, para el autor ramonense, en Concherías es posible asomarse al "alma" costarricense, trabajo que el mismo Lisímaco procura lograr en sus poemas populares, como los de Orquídeas (1904).

En su trabajo titulado "Revista Semanal de Páginas Ilustradas IV", Chavarría da cuenta de la obra de Anastasio Alfaro, a quien estima como un gran poeta que se dedica a representar seres y elementos de la naturaleza: "Él gusta de cantar las aves, los minerales y las plantas. Aprisionaría en delicados romances, si el tiempo se lo permitiera, el verde metálico de la cantárida, el oro y el carmín de los élitros del escarabajo, y las alas transparentes y azules de las libélulas." (2013, p. 490).

También Chavarría se ocupa del teatro. En "Los huérfanos. Triunfo de Ureña”, destaca el valor de la representación teatral del drama homónimo de Ureña. De esta puesta en escena resalta el acertado nivel moralizador del texto, elemento que para el poeta ramonense es un acierto, puesto que nota el esfuerzo intelectual de Ureña para procurar modelizar su sociedad.

Un último aspecto que se debe valorar de la ensayística de Lisímaco sobre crítica literaria es su decidido interés por dar a conocer los jóvenes valores de la literatura costarricense de su época. En este sentido, presenta la primera obra de Miguel Ángel Casal Acordes de mi laúd (1908), en el ensayo del mismo nombre. En él, sostiene que este texto inaugural promete un poeta de calidad, cuidadoso en la forma y acertado en el contenido: "Quien no me crea -diceque destape este precioso alcorcí de nácar y contemple los visos de las gemas que contiene." (2013, p. 504). Tal recomendación también está presente en "El estreno del domingo", donde se refiere a la primera representación teatral del drama Los intereses en peligro (1910) de Roberto Valladares, de la cual indica que "Fue un grito de rebelión de las almas fuertes, de las almas que no se prestan a la plasticidad de la conveniencias del metal y a las exigencias sociales en el campo de la publicidad" (2013, p. 512), con lo que predecía un gran porvenir a su autor en el ámbito teatral.

De esta manera, los ensayos de crítica literaria cumplieron un objetivo de divulgación de la literatura internacional entre los lectores costarricenses de principios del siglo XX, pero especialmente se ocupó Chavarría de la producción costarricense, tanto de autores reconocidos como de los jóvenes, a quienes auguraba un futuro promisiorio. Sin embargo, no son textos de orden crítico con fines de análisis objetivos, sino escrituras en las cuales el énfasis no está en el fondo de las temáticas, sino en la elaborada construcción formal que genera esa ambivalencia propia del texto ensayístico, con una fuerte carga de densidad imaginativa y de figuras retóricas, lo cual le asigna al género esa "traducción simbólica [...] de relaciones de poder y de relaciones entre campos culturales.” (Weinberg, 1995, p. 174).

\section{Los ensayos sociopolíticos e identitarios: radiografías del mal y necesidad de utopía}

Los ensayos sociopolíticos escritos por Chavarría dan cuenta del análisis y la crítica de una sociedad que erraba su rumbo y cada vez más se insertaba en complejos y perniciosos estados de corrupción y autoritarismo, producto de la primacía de los valores de cambio en vez de los de uso. En este sentido, el ensayista expresa inconformidad y quiere que su trabajo 
funcione como medio de denuncia, sin renunciar por ello a la dimensión estética del género, la cual es constitutiva del ejercicio lisimaquiano de la escritura.

En los textos "Notas ligeras. Por los pobres", "Notas ligeras. Algo sobre modas", "Semblanzas cómicas" y "Semblanzas cómicas. Los veraneos" realiza una crítica al interés desmedido de las personas por el lujo, la ostentación y el afán de ocupar un lugar destacado en los estratos altos de la sociedad.

En el primero de ellos, alude a cómo una lluvia constante del mes de diciembre del año 1904 produjo la escasez de productos básicos como el pan para los sectores más pobres, lo que provocó hambre y desesperación. Ante esto, el ensayista exclama: "la clase pobre, los desamparados de la fortuna, miran por la puerta de la miseria asomar la zarpa del hambre." (2013, p. 393), crítica que en el segundo ensayo se traslada al artificioso mundo de las modas. Condena Chavarría que mientras Estados Unidos impone la doctrina Monroe, damas de París envían sus últimas extravagancias, lo cual no significa que el autor no admire, indica, los desnudos Falconieri y de Belvedere, puesto que en ellos está presente la naturaleza sencilla y casta, nunca la artificiosidad añadida de los diseñadores franceses.

Continuando en esta dimensión crítica, el texto "Semblanzas cómicas" se refiere al tema del matrimonio como mecanismo de la continuidad generacional de la clase dominante. Por ello, uno de los principales objetivos de las familias era poder casar a sus hijos con personas que fueran de su igual condición social o superior. Sin embargo, esto conllevaba un grave problema cuando las muchachas casaderas no eran suficientemente bonitas como para atraer a un caballero adecuado. Este es el problema que expone este ensayo. En él, refiere Chavarría que doña Elena Cienfuegos tiene diez hijas, ninguna muy atractiva, y ante el paso del tiempo llega a desesperarse. La señora "asegura a pie juntillas que, el buen o mal matrimonio de las jóvenes, depende las más de las veces de los esfuerzos de las madres, y que a sus niñas las ha de casar con caballeros de alta alcurnia." (2013, p. 397). Ella se dedica a rezarle a San Rafael, a inventar paseos para mostrar a sus hijas, incurriendo en excesivos gastos sin obtener ningún resultado. El enunciador expresa su compasión por esas pobres madres que no logran casar a sus hijas con señores de la alta alcurnia.

Otra crítica de las costumbres se localiza en el texto "Semblanzas cómicas. Los veraneos", que refiere los apuros en que se ven las familias capitalinas por sentirse obligadas, en tanto sinónimo de pujanza económica y social, a trasladarse a veranear a algún lugar de playa. El enunciador relata los apuros de doña Dolores de Axila, quien presiona a su marido a realizar un sacrificio económico para que ella y sus hijas pudieran pasar una temporada en Puntarenas. Luego de unos días, y ya la señora y sus hijas fuera de San José, el pobre marido se entera de que su esposa da suntuosas fiestas en la playa y se ha declarado viuda. Este ejemplo le sirve al autor para plantear su crítica: "Se ha arraigado tanto este mal hábito de nuestra sociedad que hay familias que si no salen a veranear, se sienten humilladas y pasan el resto del año protestando de su negro destino.” (2013, p. 401).

Trasladándose al ámbito de la política, la ensayística del autor realiza un diagnóstico poco esperanzador, puesto que para él esta actividad constituye una grave enfermedad degenerativa, en el sentido de que despierta en el ser humano sus peores sentimientos y sus planes más destructivos. En su trabajo "Amagos políticos" recurre al intertexto cervantino para mostrar que dicha práctica transforma a la personas y las transporta a un mundo de fantasía: "Ella es como los libros de caballería al manchego inmortalizado por Cervantes, vuelve locos a muchos y los hace soñar con triunfos inverosímiles." (2013, p. 412). A pesar de ello, Chavarría 
insiste en no perder la utopía de fe en un futuro promisorio donde los valores reinantes sean la solidaridad y la fraternidad. Así lo expresa en el ensayo "Conversando":

\begin{abstract}
Y no es que voy a componer un canto al humanitarismo. Pero la verdad es que el hombre de esta época, conforme avanza el progreso, parece odiarse mayormente y crea e inventa, no para el bien solidario, sino para la destrucción que le reporte ventajas propias. Los imitadores se contagian fácilmente y corren a poner en práctica los métodos del género vividor que levanta el estandarte del “iprimun est vivere!”. Enmascaradas las ideas, van del brazo de la política burlando los sentimientos de fraternidad, que son los del verdadero patriotismo. (2013, p. 441)
\end{abstract}

Una de las peores manifestaciones de la política es su vínculo con el poder, y, especialmente, el militarismo que ha sido tan devastador en la historia latinoamericana. Sorprendido por esa evidente relación entre política y militarismo en la Centroamérica de principios del siglo XX y satisfecho de que Costa Rica sea una excepción, previene al país de esta práctica sanguinaria en el ensayo "Más todavía":

Ya que nuestro país ha tenido mejor suerte en este caso, preciso es que nos preparemos a contener los avances que el militarismo pudiera hacer. No abramos las puertas a esos generales ambulantes que apenas llegan a otra tierra se dirigen al gobierno ofreciéndole su adhesión incondicional. (2013, p. 455)

Esta asociación entre política y militarismo la miraba con mucha preocupación en el área centroamericana, y específicamente pensando en el proyecto de la Unión Federal, puesto que estimaba posible que tal anhelo histórico fuera una estrategia de los sectores militares para dominar la región. Por ello el ensayista fue un declarado opositor de dicho proyecto, máxime cuando era impulsado por los gobiernos de Nicaragua, El Salvador, Honduras y Guatemala, países que han tenido fuertes estructuras militares que han dominado el gobierno:

Queremos la Unión, cuando estos pueblos no se hallen desmoralizados y tenga garantías el ciudadano libre: cuando haya gobernantes elevados por el sufragio popular: cuando, y esto es lo principal, no impere el militarismo en estas Repúblicas, porque el militarismo es el sostenedor de las dictaduras. (2013, p. 460)

Por otra parte, Chavarría dedicó un texto al papel de los sectores populares en Costa Rica: "Para ellos", en el cual criticó la actitud de los partidos políticos al procurar, en todo tiempo electoral, manipularlos con falsas promesas e intentar comprar sus conciencias, lo que era un evidente irrespeto tanto para ellos como personas dignas como para con el sistema democrático. Indica el ensayista que al calor de las campañas se forman asociaciones y gremios alrededor de partidos personalistas, organizaciones que no tienen más vida ni objetivos que ir a votar, y cuando eso pasa, fenece todo el sentido organizacional. Por estas razones, el autor propugna porque se respete al trabajador. "Queremos que abra los ojos el obrero y no se preste más de fantoche." (2013, p. 452), afirma con total convicción.

Para Chavarría es un deber patriótico trabajar en conjunto como sociedad para resolver estos serios problemas políticos. En esta labor, el papel de la prensa resulta fundamental, puesto que es el medio que puede coadyuvar a la orientación y la toma de conciencia del ciudadano. En el ensayo "El periodismo" afirma que la prensa debe ilustrar y ayudar a "difundir por doquiera la luz del adelanto." (2013, p. 433), y en "Seguimos" propone que los medios deben responder a las necesidades de una vida nueva, distante del militarismo y la corrupción, y cercana a los requerimientos democráticos de una sociedad moderna, un periodismo que alumbre "una alborada de energías que brillará en el cielo de la patria abriendo risueños horizontes al progreso.” (2013,p. 455). Estamos en el terreno de la utopía, proyección necesaria para el diseño del futuro nacional, en una época que veía la modernización del país como un camino posible y justo. 
Por otra parte, en "Notas ligeras. Ambición humana”, expresa Chavarría un decidido antiimperialismo. Protesta por la desmedida ambición de los Estados Unidos, país poderoso que a principios del siglo XX se expandía conquistando variadas regiones más débiles: "La nación yankee, la gigante nación del Nuevo Mundo, nuestra hermana mayor, la grande, la poderosa, se hace dueña de sus hermanas pequeñas, las convierte en esclavas en nombre de la patria universal." (2013, p. 396), lo cual le permite exhortar a la atención, ya que mira la libertad americana en peligro. Denuncia, también, los atropellos efectuados por los norteamericanos en Colombia y pone en alerta por lo que pueda ocurrir en Centroamérica. Este ensayo forma parte de la preocupación de los intelectuales latinoamericanos por los avances imperialistas estadounidenses que se convirtieron en realidades efectivas y en temores angustiantes para los pueblos de herencia española y portuguesa. ${ }^{6}$ No cabe duda de que esta posición de Chavarría y su crítica de los valores mercantiles de la sociedad liberal lo aúnan al grupo de pensadores que se distingue de la Generación del Olimpo y que Gerardo Morales denomina "Los nuevos intelectuales", una destacada generación crítica con el pasado reciente y con proyectos sociales y políticos de orden democrático para el país y el continente. ${ }^{7}$

Estos ensayos de orden sociopolítico son una construcción intelectual sobre la identidad costarricense. Como bien lo expresa Roberto Hozven (1985, pp. 67-68), la identidad nacional no se constituye como un objeto de conocimiento unificado proveniente de un sustrato nacional popular preservado por una memoria colectiva o cristalizado en objetos tradicionales y legitimados por la tradición, la razón, la alta o baja cultura, antes bien, es una construcción discursiva de orden performativo y elaborada a posteriori. ${ }^{8}$ En este sentido, el ensayo es uno de los géneros en los cuales se constata mayormente esta dimensión constructiva de carácter histórico.

En Chavarría, esta constitución discursiva también remite a la dialéctica entre la vida y la muerte. El primer ámbito lo ocupa su ensayística que mira la utopía social como el único camino justo para la humanidad. En este eje semántico, la representación de la naturaleza americana como espacio de vida saludable y pródigo es fundamental. En el ensayo "Fiesta de los campos. En el trópico", la vida se manifiesta en toda su alborozada extensión, por medio de un estilizado lenguaje poético que rebosa de imágenes vitales:

\footnotetext{
Grandes columnas de humo que arremolina el viento, se levantan de las abras y rastrojos preparados para las siembras; esos vórtices plomizos se yerguen de las quemas que, cual serpientes ígneas, allá en las noches veraniegas, se retuercen en los flancos de los montes y bajan chisporroteando, lamiendo los troncos y las piedras con gigantescas lenguas de fuego, por las profundas hondonadas y por las anchas vegas hasta detenerse en las riberas de los ríos, en donde languidecen y mueren arrojando a las corrientes y remansos ramilletes de topacios y rubíes. (2013, p. 474)
}

Pero al lado de esta incontenible abundancia vital presente en la naturaleza, la vida social tiene otra cara: la de los excluidos, que es mostrada en el ensayo "Sombras humanas". Esta representación permite apreciar con mayor claridad la dimensión humanística de la escritura del autor. En el texto, el enunciador se conduele por las miserias que arrastran dos desvalidos quienes viven en la calle gracias a la caridad. Lisímaco se une a sus desgracias y reflexiona sobre esa dialéctica entre la riqueza y la pobreza producto de la injusta distribución social de los bienes materiales. Afirma: "Esas dos sombras humanas que se unen y se comprenden son como un símbolo: -Un anciano cuasi inválido guiado por un ciego. Mejor no podría nadie representar la realidad de la existencia humana." (2013, p. 477). Y es que, efectivamente, para Chavarría la vida es un espacio dialéctico de contradicciones donde abunda la negación de la justicia, a pesar de que él mira con esperanzas el futuro y asume la utopía como medio de salvación. Sin embargo, es consciente de que al lado de la vida que palpita asoma su rostro, 
siempre, la muerte. Por ello en el ensayo "Canción de la muerte" afirma que una calavera le "ha enseñado a despreciar la vida viviéndola y me ha dicho en su lenguaje misterioso que la muerte de la materia humana no es más que un fenómeno de transformación, que el Cosmos es infinito, que el Universo nunca muere." (2013, p. 467). Es decir, que vida/muerte son los dos componentes de la vida, ya que para el autor, como bien lo expresó, siguiendo el pensamiento teosófico tan valorado en su época, en el reconocido poema "Espigas y azucenas" de 1909:

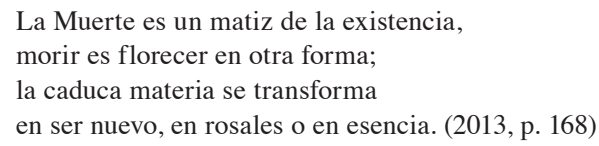

\section{Conclusión}

La ensayística de Lisímaco Chavarría constituye un entramado discursivo multiforme y dialógico, en el cual se abordan distintas temáticas de gran relevancia para la cultura costarricense de finales del siglo XIX y principios del XX. Sus ensayos se inscriben dentro de la renovación del pensamiento nacional producida por el surgimiento de una nueva intelectualidad crítica que se distanció política e ideológicamente del pensamiento liberal de la Generación del Olimpo. Chavarría, junto con Joaquín García Monge, José María Zeledón, Carmen Lyra, Omar Dengo y un destacado grupo de artistas y pensadores, procuró diseñar nuevos caminos para la sociedad costarricense, senderos que se alejaran de la exclusión social y consideraran la incorporación de los sectores no hegemónicos.

En este esfuerzo, la práctica ensayística del autor se ocupó de temas centrales para el desarrollo del país: el periodismo, la educación, la herencia indígena, las artes, la crítica literaria, la política y la identidad cultural. Del primer aspecto, Chavarría destacó la necesidad de la existencia de unos medios comunicativos que fueran críticos y que tuvieran la capacidad de orientar y enseñar a las grandes mayorías.

En cuanto a la educación, el autor siempre la consideró como el único camino posible para el desarrollo nacional, práctica que debía ser revalorada por quienes detentaban el poder para que su propagación incidiera en la formación de ciudadanos críticos y libres, así como también fuera un medio de ascenso social para los sectores más pobres.

La ensayística dedicada a las artes plantea una teoría estética que contempla la expresión artística como una esencia intemporal que se manifiesta en realizaciones concretas, por ello no importa tanto la modalidad expresiva del arte (música, pintura, escultura, poesía) sino que lo más valioso es que cada una de ellas pueda ser un vehículo para manifestar esa dimensión de lo estético que alimenta el espíritu transportándolo a universos distanciados de la vida cotidiana.

Por su parte, los trabajos sobre crítica literaria tienen la misión de dar a conocer a su época las corrientes y autores más destacados del medio internacional y nacional. Este ejercicio crítico es abordado por Chavarría mediante una amplia erudición intertextual que le permite hacer valoraciones recurriendo a modelos comparativos de todas las épocas y culturas, pero prefiriendo las literaturas y las artes clásicas. A esto hay que agregar el esfuerzo del autor por abrir espacios a los jóvenes valores, trabajo que desarrolló en los diferentes medios en los que tuvo acceso.

En sus ensayos sociopolíticos se observa un doble interés. Por un lado, la crítica aguda del autoritarismo, el militarismo y la corrupción en la práctica política; y por el otro, una 
apuesta a la democracia, a la justicia y un profundo deseo de utopía, para que cambien las concepciones del ejercicio político y este sea concebido y asumido como una oportunidad de trabajar para mejorar las condiciones de vida de los más necesitados, única forma de acceder al progreso con justicia.

Estos ensayos sociopolíticos constituyen una parte de la construcción discursiva sobre la identidad cultural costarricense, los cuales, junto con las reflexiones sobre la naturaleza, la vida y la muerte conforman un destacado corpus en el cual Chavarría asume la función referencial del ensayo, pero sin subordinarla a un ejercicio instrumental, debido a que la dimensión estética del texto fue un aspecto determinante en la práctica literaria del autor. Para él, la escritura siempre fue un espacio de ascenso al reino plurivalente de la poesía.

\section{Notas}

1. Esta obra fue publicada en San José por la Imprenta de Avelino Alsina.

2. Junto con su primera esposa, Rosa Corrales, Chavarría trabajó en 1900 en la Escuela de Tabarcia de Mora, San José. Al año siguiente fueron nombrados en la Escuela de Piedades de Santa Ana, Rosa como maestra de la Escuela de Niñas y Lisímaco como Director de la Escuela de Varones, cargos que desempeñaron hasta el año 1903. Véase al respecto: Francisco Rodríguez Cascante. "Estudio Introductorio". Lisímaco Chavarría. Obras completas. San José: Editorial de la Universidad de Costa Rica, 2013, 16-17.

3. Al respecto, indica Iván Molina: "Para comprender del descenso entre 1885 y 1911, y el alza posterior en el porcentaje de titulados, es preciso considerar los dos siguientes aspectos. Primero, la creciente demanda de personal docente, generada por la reforma en las primeras tres décadas posteriores a 1886 [...] no pudo ser satisfecha por las secciones normales de los colegios ni por la Escuela Normal, razón por la cual fue necesario contratar a una creciente proporción de personas no tituladas.” (2008, p. 222).

4. Estos textos se encuentran en: Lisímaco Chavarría. Obras completas. Tomo II. San José: Editorial de la Universidad de Costa Rica, 2013, 365-540. En adelante, todas las citas a los ensayos del autor provienen de esta edición, por lo cual, en las referencias, no se indicará el tomo.

5. Véase, por ejemplo, esta comparación que efectúa Luis Cardoza y Aragón en su autobiografía, entre la niñez y la adultez: "el niño sueña soñando y sus cosas se oponen a la diligencia del adulto que únicamente percibe su provecho. [...] El adulto, sordo y sin voz, féretro ciego. El niño avanza con su incendio a todas partes para iluminar el rostro de las cosas" (1986, p. 84). También el poema más conocido del poeta español Jaime Gil de Biedma titulado "No volveré a ser joven" asume esta distinción: "Que la vida iba en serio/ uno lo empieza a comprender más tarde/ -como todos los jóvenes, yo vine a llevarme la vida por delante./ Dejar huella quería / y marcharme entre aplausos/ -envejecer, morir, eran tan solo/ las dimensiones del teatro." (1989, p. 91).

6. Al respecto véase: Eduardo Devés Valdés. El pensamiento latinoamericano en el siglo XX. Entre la modernización y la identidad. Tomo I. Del Ariel de Rodó a la CEPAL (1900-1950). Buenos Aires: Editorial Biblos, 2000, páginas 179 y siguientes. También: Miguel Rojas Mix. Los cien nombres de América. San José: Editorial de la Universidad de Costa Rica, 1997, página 357 y siguientes.

7. Considérese: Gerardo Morales. Cultura oligárquica y nueva intelectualidad en Costa Rica: 1880 -1914. Heredia: Editorial de la Universidad Nacional, 1995, página 109 y siguientes.

8. Refiriéndose a los estudios sobre las identidades, afirma el autor: "En realidad, todos coinciden en que la identidad nacional se forma a posteriori, a la manera de un mosaico expositivo retroalimentado por la historia. A su vez, el ensayo reinventa esa historia diariamente. Esta identidad nacional-mosaico (la imagen es de José Martí), resultado de la fragmentada convergencia de todos los niveles anteriores, es actualizada corporal, ritual y escrituralmente por el sujeto hispanoamericano de un modo inconsciente, ambiguo y nunca dialéctico. Su experiencia de la cultura (choques con la administración pública, resentimientos o gratificaciones de clase, percepción de la justicia, contrapuesta al sentido común de la injusticia, etc.) es discontinua y reajustada con respecto a la conciencia social por la que la procesa." (Hozven, 1985, p. 68). 


\section{Bibliografía}

Arizpe, L. (1993). “El ‘indio’: mito, profecía, prisión”. Por L. Zea. (Ed.). América Latina en sus ideas. (3 ed.). (333-334). México: Siglo Veintiuno Editores.

Cardoza y Aragón, L. (1986). El río, novelas de caballería. México: Fondo de Cultura Económica.

Chavarría-Palma, L. (2013). Obras completas. (Vol. I-II). San José: Editorial de la Universidad de Costa Rica.

Devés-Valdés, E. (2000). El pensamiento latinoamericano en el siglo XX. Entre la modernización y la identidad. Del Ariel de Rodó a la CEPAL (1900-1950). (Vol. I). Buenos Aires: Editorial Biblos.

Earle, P. (1982). “El ensayo hispanoamericano, del modernismo a la modernidad”. Revista Iberoamericana. 48 (118), 47-57.

Fernández, T. (1990). Los géneros ensayísticos hispanoamericanos. Madrid: Taurus.

Gil de Biedma, J. (1989). Volver. Madrid: Cátedra.

González-Picado, J. (1993). El ensayo: sus formas y contenidos. San José: Editorial Fernández Arce.

Hirshbein, C. (1998). El ensayo literario en Hispanoamérica. Su expresión en Venezuela. Actas del XIII congreso de la Asociación Internacional de Hispanistas. (698-705). Madrid: Editorial Castalia.

Hozven, R. (1985). "El ensayo hispanoamericano y sus alegorías". Revista Chilena de Literatura, 55-78.

Magallón-Anaya, M. (1993). El ensayo pedagógico en América Latina: el proyecto educativo de José Vasconcelos. El ensayo en Nuestra América. (Vol I). (233-265). México: Universidad Nacional Autónoma de México.

Maíz, C. (2013). "Demonios, profetas y mártires: restos bíblicos en la ensayística hispanoamericana moderna”. Literatura y Lingüística. 27, 67-82.

Molina, I. (2008). "Educación y sociedad en Costa Rica: de 1821 al presente (una historia no autorizada)". Diálogos. Revista Electrónica de Historia. 8 (2), 148-356. http://historia. fcs.ucr.ac.cr/dialogos.htm [Consulta 8 de octubre de 2015].

Morales, G. (1995). Cultura oligárquica y nueva intelectualidad en Costa Rica: 1880-1914. Heredia: Editorial de la Universidad Nacional.

Rodríguez-Cascante, F. (2013). "Estudio Introductorio”. L. Chavarría. Obras completas. (Vol I). (1-137). San José: Editorial de la Universidad de Costa Rica.

Rojas-Mix, M. (1997). Los cien nombres de América. San José: Editorial de la Universidad de Costa Rica.

Weinberg, L. (1995). Ensayo y simbólica. El ensayo iberoamericano. (Vol 4). (169-175). México: Universidad Nacional Autónoma de México.

Weinberg, L. (2006). Situación del ensayo. México: Universidad Nacional Autónoma de México. 